\title{
Influence of inspiratory threshold load on cardiovascular responses to controlled breathing at $0.1 \mathrm{~Hz}$
}

Citation for published version (APA):

Gholamrezaei, A., Van Diest, I., Aziz, Q., Vlaeyen, J. W. S., \& Van Oudenhove, L. (2019). Influence of inspiratory threshold load on cardiovascular responses to controlled breathing at $0.1 \mathrm{~Hz}$. Psychophysiology, 56(11), [e13447]. https://doi.org/10.1111/psyp.13447

Document status and date:

Published: 01/11/2019

DOI:

10.1111/psyp. 13447

Document Version:

Publisher's PDF, also known as Version of record

Document license:

Taverne

Please check the document version of this publication:

- A submitted manuscript is the version of the article upon submission and before peer-review. There can be important differences between the submitted version and the official published version of record.

People interested in the research are advised to contact the author for the final version of the publication, or visit the DOI to the publisher's website.

- The final author version and the galley proof are versions of the publication after peer review.

- The final published version features the final layout of the paper including the volume, issue and page numbers.

Link to publication

\footnotetext{
General rights rights.

- You may freely distribute the URL identifying the publication in the public portal. please follow below link for the End User Agreement:

www.umlib.nl/taverne-license

Take down policy

If you believe that this document breaches copyright please contact us at:

repository@maastrichtuniversity.nl

providing details and we will investigate your claim.
}

Copyright and moral rights for the publications made accessible in the public portal are retained by the authors and/or other copyright owners and it is a condition of accessing publications that users recognise and abide by the legal requirements associated with these

- Users may download and print one copy of any publication from the public portal for the purpose of private study or research.

- You may not further distribute the material or use it for any profit-making activity or commercial gain

If the publication is distributed under the terms of Article $25 \mathrm{fa}$ of the Dutch Copyright Act, indicated by the "Taverne" license above, 


\title{
Influence of inspiratory threshold load on cardiovascular responses to controlled breathing at $0.1 \mathrm{~Hz}$
}

\author{
Ali Gholamrezaei ${ }^{1,2}$ (D) | Ilse Van Diest ${ }^{2}$ (D) | Qasim Aziz $^{3}$ | Johan W. S. Vlaeyen ${ }^{2}$ | \\ Lukas Van Oudenhove ${ }^{1}$
}

${ }^{1}$ Laboratory for Brain-Gut Axis Studies (LaBGAS), Translational Research Center for Gastrointestinal Disorders (TARGID), Department of Chronic Diseases,

Metabolism and Ageing, University of Leuven, Leuven, Belgium

${ }^{2}$ Health Psychology Research Group, Faculty of Psychology and Educational Sciences, University of Leuven, Leuven, Belgium

${ }^{3}$ Centre for Neuroscience and Trauma, Blizard Institute, Wingate Institute of Neurogastroeneterology, Queen Mary University of London, London, UK

\section{Correspondence}

Ali Gholamrezaei, Health Psychology Research Group, Faculty of Psychology and Educational Sciences, Tiensestraat 102, Box 3726, 3000 Leuven, Belgium.

Email: ali.gholamrezaei@kuleuven.be

Funding information

Research Council KU Leuven

(DBOF/14/020); Flemish Government,

Belgium "Asthenes" long-term structural funding-Methusalem grant (Meth/15/011)

\begin{abstract}
Slow, deep breathing is being used as a self-management intervention for various health conditions including pain and hypertension. Stimulation of the arterial baroreceptors and increased vagal modulation are among the proposed mechanisms for the therapeutic effects of slow, deep breathing. We investigated whether adding inspiratory threshold load can enhance the cardiovascular responses to controlled breathing at the frequency of $0.1 \mathrm{~Hz}$, a common form of slow, deep breathing. Healthy volunteers $(N=29)$ performed controlled breathing at $0.1 \mathrm{~Hz}$ ( 6 breaths/minute) without load and with inspiratory threshold loads of $5 \mathrm{cmH}_{2} \mathrm{O}$ and $10 \mathrm{cmH}_{2} \mathrm{O}$. Respiratory airflow, heart rate, and blood pressure were continuously recorded. The amplitude of the systolic blood pressure variation during respiratory cycles increased with increasing loads. Respiratory sinus arrhythmia was higher during controlled breathing at $0.1 \mathrm{~Hz}$ with the load of $10 \mathrm{cmH}_{2} \mathrm{O}$ compared to without load. Baroreflex sensitivity was not affected by loads. The effect of loads on respiratory sinus arrhythmia was mediated by increasing the amplitude of systolic blood pressure variation during respiratory cycles. These results suggest that applying small inspiratory threshold loads during controlled breathing at $0.1 \mathrm{~Hz}$ increases cardiac vagal modulation by this breathing exercise. This effect seems to be mediated by stronger stimulation of the arterial baroreceptors because of larger systolic blood pressure swings along the respiratory cycle. The potential benefit of long-term practice of controlled breathing at $0.1 \mathrm{~Hz}$ with inspiratory threshold loads on baroreflex function and cardiac vagal control needs to be investigated, particularly in pain and hypertension patients.
\end{abstract}

\section{K E Y W O R D S}

autonomic, baroreflex, breathing exercises, heart rate variability, respiratory sinus arrhythmia, vagal

\section{1 | INTRODUCTION}

Breathing exercises, including conscious control and alteration of the rate, rhythm, and/or depth of the breathing, are common components of various mind-body, psychological, and behavioral therapies (Jackson, 2015). Notably, slow, deep breathing $(\mathrm{SDB})^{1}$ is commonly being used as a selfmanagement intervention in various psychological and medical conditions including, but not limited to, stress,

\footnotetext{
${ }^{1}$ Slow, deep breathing in this manuscript refers to controlled breathing at the frequency of $\sim 0.1 \mathrm{~Hz}$ ( $\sim 6$ breaths/minute).
} 
anxiety, hypertension, and pain (Jafari, Courtois, Van den Bergh, Vlaeyen, \& Van Diest, 2017; Kim, Burge, Mermier, Kravitz, \& Schneider, 2016; Zou et al., 2017). Studies have shown beneficial effects of SDB in hypertension patients (Zou et al., 2017) and potential benefits of this breathing exercise for pain management (Jafari et al., 2017). However, the underlying mechanisms are not completely understood and may be multifactorial (Jafari et al., 2017).

Experimental studies have shown a profound increase in heart rate variability (HRV, suggested as an index of cardiac vagal modulation) during SDB (e.g., Kromenacker, Sanova, Marcus, Allen, \& Lane, 2018). Although the underlying mechanisms are not yet clear, both central and peripheral pathways seem to be involved in the cardiac vagal response to SDB. The systolic blood pressure drops by 2 to $5 \mathrm{mmHg}$ during normal inspiration, while it falls by up to $15 \mathrm{mmHg}$ during deep inspiration, mainly as a result of more reduced intrathoracic pressure (Sin, Galletly, \& Tzeng, 2010). This increase in blood pressure swings over the respiratory cycle, together with the reflexive response via the arterial baroreflex (which is responsible to regulate acute arterial blood pressure changes), is one of the possible mechanisms for the observed increase in cardiac vagal modulation during SDB (Horsman, Peebles, \& Tzeng, 2015; Sin et al., 2010; Stankovski, Cooke, Rudas, Stefanovska, \& Eckberg, 2013).

Several techniques are available to perform SDB. Some of the traditional breathing exercises in yoga practice include a (respiratory) load during inspiration and/or expiration. Examples include breathing through one nostril in the unilateral/alternate nostril breathing technique or narrowing the glottis in the Ujjayi breathing technique (Mason et al., 2013; Raghuraj \& Telles, 2008). Such techniques are supposed to be helpful in controlling and prolonging respiration and lowering the respiratory rate. In addition, applying a respiratory load may alter cardiorespiratory interactions during SDB. Loaded breathing augments alterations in intrathoracic pressure and blood pressure swings along the respiratory cycle, which in turn may lead to stronger stimulation of the arterial baroreceptors and increased cardiac vagal modulation (Calabrese, Perrault, Dinh, Eberhard, \& Benchetrit, 2000). Therefore, respiratory loads may increase the effectiveness of SDB in patients with pain and hypertension, where stimulation of the arterial baroreceptors and increased vagal modulation are suggested as possible mechanisms involved in the reduction of pain or hypertension (Cernes \& Zimlichman, 2015; Jafari et al., 2017).

Only few experimental studies have evaluated the effects of respiratory loads during inspiration on cardiovascular responses. These studies report that adding inspiratory loads to breathing at a normal breathing frequency increased stroke volume and blood pressure (mainly as a result of increased venous return to the heart), but no significant change in cardiac vagal modulation has been observed (Convertino, Ratliff,
Ryan, Cooke et al., 2004; Convertino, Ratliff, Ryan, Doerr et al., 2004; Cooke, Lurie, Rohrer, \& Convertino, 2006; Ryan, Cooke, Rickards, Lurie, \& Convertino, 2008). Considering that the arterial baroreflex response is influenced by the frequency of oscillations in blood pressure (Horsman et al., 2015; Pitzalis, 1998), applying an inspiratory load at lower breathing frequencies (i.e. $\sim 0.1 \mathrm{~Hz}$ or $\sim 6$ breaths/minute) may enhance the effects of the SDB exercise on cardiac vagal modulation. To our knowledge, this has not yet been experimentally investigated. In this study, we evaluated the effects of inspiratory threshold load on cardiovascular responses during controlled breathing at the frequency of $0.1 \mathrm{~Hz}$. We hypothesized that applying an inspiratory threshold load would increase cardiac vagal modulation during controlled breathing at $0.1 \mathrm{~Hz}$ and that this effect is mediated by larger blood pressure swings during respiratory cycles, suggesting stronger stimulation of the arterial baroreceptors.

\section{$2 \mid$ METHOD}

\section{1 | Participants}

This experimental study was conducted in the laboratory of the Health Psychology Research Group, KU Leuven (Leuven, Belgium). Healthy male and female volunteers aged 18-45 years were invited to participate. Exclusion criteria included having any of the following self-reported conditions: cardiovascular, respiratory, or neurological diseases, acute or chronic pain conditions, psychiatric disorders, regular medication use other than contraceptives, pregnancy, current smoking or any other nicotine consumption, and practicing yoga, meditation, relaxation, or mindfulness on a regular basis. Also, those with body mass index (BMI, based on self-reported weight and height) of $<18.5$ (underweight) or $>30 \mathrm{~kg} / \mathrm{m}^{2}$ (obese) and those with score of $8+$ in any of the subscales of the Hospital Anxiety and Depression scale were not included in the study (Bjelland, Dahl, Haug, \& Neckelmann, 2002). Participants were asked to refrain from strenuous exercise and from caffeine and alcohol intake for at least $12 \mathrm{hr}$ prior to testing. The study was approved by the Social and Societal Ethics Committee, KU Leuven (\#G-2016 02 478), and informed consent was obtained from all participants. Testing was performed in a single $2-\mathrm{hr}$ session between 9 am and $5 \mathrm{pm}$ in a sound-attenuated and temperature-controlled $\left(22-25^{\circ} \mathrm{C}\right)$ room (see online supporting information, Appendix S1, section S2.1).

\section{2 $\quad$ Instruments and measurements}

\subsection{1 $\quad$ Respiratory apparatus and measures}

Participants breathed through the mouth and a breathing circuit (Appendix S1, section S2.2.1). The flow-independent 
threshold load (Threshold PEP, Respironics Inc., NJ) was attached to the end of the breathing circuit to be used as an inspiratory load. With this type of load, participants must generate a certain negative pressure to open a valve (enabling inspiration) and maintain that pressure minimally to keep the valve open (during inspiration). We chose a threshold load since, in contrast to a resistive load, a constant pressure can be achieved by threshold loading independent of inspiratory airflow (Gosselink, Wagenaar, \& Decramer, 1996). Respiratory airflow was measured by the pneumotach connected to a pressure transducer and amplifier (series 1110, Hans Rudolph Inc., Shawnee, USA). Expiratory carbon dioxide $\left(\mathrm{CO}_{2}\right)$ was measured continuously by a $\mathrm{CO}_{2}$ analyzer (VacuMed, Ventura, CA).

\subsection{2 | Electrocardiography and blood pressure}

The electrocardiography (ECG) signal was recorded in Lead II configuration (V75-04, Coulbourn Instruments, Allentown, PA). Arterial pressure was measured continuously at the middle or ring finger of the left hand (Portapres Model-2, TNO TPD Biomedical Instrumentation, Amsterdam, the Netherlands; Appendix S1, S2.2.2). All signals were recorded and digitized at $1 \mathrm{KHz}$ sampling rate (16-bit PCI-6221 card, National Instruments, TX) using AFFECT software version 4.0 (KU Leuven, Belgium; Spruyt, Clarysse, Vansteenwegen, Baeyens, \& Hermans, 2010).

\subsection{3 | Self-reported measurements}

Dyspnea (phrased as difficulty in breathing) was measured using the modified BORG scale with scores from 0 (nothing at all) to 10 (intolerable; Borg, 1982). Emotional valence (pleasant vs. unpleasant) and arousal (calm vs. excited) were measured by the 9-point Self-Assessment Manikin scale and were scored from 5 to -5 , having 0 score as a neutral state (Bradley \& Lang, 1994).

\section{$2.3 \mid$ Procedures}

\subsection{1 | Training}

Participants were seated in a comfortable chair with their upper body and arms being supported. After instructions (Appendix S1, S2.3.1), participants were trained by practicing controlled breathing at $0.1 \mathrm{~Hz}$ with no load, with a load of $5 \mathrm{cmH}_{2} \mathrm{O}$, and then with a load of $10 \mathrm{cmH}_{2} \mathrm{O}$, each for $1 \mathrm{~min}$, followed by ratings for dyspnea and emotional valence and arousal. The inspiration to expiration ratio was 1:2 (Van Diest et al., 2014). If a participant rated his/her dyspnea higher than moderate on the BORG scale, the load was not used in the subsequent main test. Instruments for physiological recordings were attached, participants were familiarized with the measurements and the main experimental procedure, and then rested for 5 min before the main test.

\subsection{2 | Main test}

The study design was within subject, and the main test included five breathing conditions: uncontrolled breathing, controlled breathing at $0.23 \mathrm{~Hz}$ (14 breaths/minute), and controlled breathing at $0.1 \mathrm{~Hz}$ (6 breaths/minute) without load and with the loads of $5 \mathrm{cmH}_{2} \mathrm{O}$ and $10 \mathrm{cmH}_{2} \mathrm{O}$, each for $3 \mathrm{~min}$, in random order (Appendix S1, S2.3.2). The uncontrolled breathing and controlled breathing at $0.23 \mathrm{~Hz}$ conditions were used for aims not directly related to this study, and therefore the results of these conditions are reported in the supporting information. Duration for each breathing condition (3 $\mathrm{min}$ ) was based on a pilot testing considering the comfort of breathing against various loads $\left(5,10\right.$, and $\left.15 \mathrm{cmH}_{2} \mathrm{O}\right)$. Each condition was followed by a 5-min rest. Physiological measures were continuously recorded during each condition, and self-reported measures were assessed after completion of each condition.

\subsection{Data reduction and analysis}

All physiological signals were processed using custom-written algorithms in MATLAB software (R2018b, Mathworks, Inc., Natick, MA).

\subsection{1 | Respiratory measures}

Respiratory times (inspiration and total respiratory durations), tidal volume, pressure, and end-tidal $\mathrm{CO}_{2}\left(\mathrm{EtCO}_{2}\right)$ were extracted for each respiratory cycle. Minute ventilation was calculated as tidal volume $\times$ respiratory rate per minute. Power spectral analysis (Burg's method) was performed (for visualization purpose) after converting respiratory flow to a continuous respiratory volume time series, indicating instantaneous lung volume (Appendix S1, S2.4.1).

\subsection{2 | Heart rate variability}

RR intervals were extracted from the ECG signal, and analysis of HRV was performed for time-domain and frequency-domain indexes according to the published guidelines (Task Force of the European Society of Cardiology and the American Society of Pacing and Electrophysiology, 1996). Averaged RR intervals (representing tonic cardiac autonomic activity) and root mean square of the successive differences (RMSSD; representing vagally mediated HRV) were calculated for each breathing condition (de Geus, Gianaros, Brindle, Jennings, \& Berntson, 2019; Grossman \& Taylor, 2007). Power spectral analysis (Burg's method) was 
performed on the RR-interval time series, and data were averaged over the low frequency (LF; $\geq 0.04$ and $<0.15 \mathrm{~Hz}$ ) and high frequency (HF; $\geq 0.15$ and $<0.4 \mathrm{~Hz}$ ) bands (Appendix $\mathrm{S} 1, \mathrm{~S} 2.4 .2)$. Considering the frequency of controlled breathing at $0.1 \mathrm{~Hz}$, only the result of HRV at LF band (LF-HRV) is reported in the main text. A recent pharmacological blockade study showed that the LF-HRV during SDB is indicative of cardiac vagal modulation (Kromenacker et al., 2018).

Respiratory sinus arrhythmia (RSA, representing respiratory modulation of cardiac vagal activity) was calculated for each respiratory cycle with the peak-to-valley method (Sin et al., 2010). While the above-mentioned time-domain and frequency-domain indexes provide information about overall HRV in each breathing condition (single level), the RSA provides better temporal resolution (multilevel) for mediation analysis (see section 2.5, Statistical analyses).

\subsection{3 | Blood pressure variability}

Beat-to-beat systolic (SBP) and diastolic (DBP) blood pressures were extracted from the arterial pressure wave signal (Appendix S1, S2.4.3). Averages of SBPs and DBPs were calculated for each breathing condition. The amplitude of SBP variation was calculated for each respiratory cycle with the peak-to-valley method (Sin et al., 2010). Spectral analysis for SBP time series was performed in the same way as for the RR intervals. We visualized SBPs and RR intervals over all respiratory cycles to explore the effect of loads on cardiorespiratory dynamics (Sin et al., 2010; Appendix S1, 2.4.3).

\subsection{4 | Baroreflex sensitivity}

Cardiovagal baroreflex sensitivity (BRS) was calculated using the sequence method (La Rovere, Pinna, \& Raczak, 2008). The following criteria were applied: $\geq 1 \mathrm{mmHg}$ change in successive SBPs; $\geq 5$ ms change in successive RR intervals; $\geq 3$ heartbeats in each sequence; $\geq .8$ coefficient of correlation between changes in SBPs and RR intervals. The lag (delay) between SBP and RR interval time series was considered as +1 (see Figure S1 for clarification; Davies et al., 2001). The slope of the regression line between SBPs and $\mathrm{RR}$ intervals in each sequence was taken as the baroreflex gain (sensitivity) for that sequence (unit $\mathrm{ms} / \mathrm{mmHg}$ ). Only the up sequences (parallel increase in SBPs and RR intervals) were analyzed, since such sequences represent stimulation of the arterial baroreceptors. The BRS was averaged over the sequences in each breathing condition (Appendix S1, S2.4.4).

\section{5 | Statistical analyses}

We expected a medium effect size (Cohen's $f=0.25$ ) for the hypothesized influence of inspiratory threshold loads during controlled breathing at $0.1 \mathrm{~Hz}$ (Sin et al., 2010) on blood pressure variability (BPV) and HRV measures. Using $\mathrm{G}^{*}$ Power software (Düsseldorf, Germany) for repeated measures analyses of variance (ANOVAs), the required sample size to detect an effect size of 0.25 with a power of 0.80 and alpha (Type I error) of 0.05 was estimated at 28 .

The study primary outcomes were BPV and HRV indexes. Secondary outcomes included respiratory measures, BRS, and the self-reported dyspnea and emotional valence and arousal. Marginal linear mixed models with breathing condition as a within-subject factor were performed. Pairwise contrasts were performed wherever the effect of breathing condition was significant. The Holm-Bonferroni (stepdown) method was applied for correcting $p$ values for multiple comparisons (Holm, 1979). Results of contrasts are reported as differences of the least squares means (DLSM) and standard error (SE). For the effect size, Cohen's $d$ was calculated based on the results of contrasts (Lakens, 2013). Findings of the uncontrolled breathing and controlled breathing at $0.23 \mathrm{~Hz}$ conditions are reported in Appendix S1, Results. Details of pairwise comparisons not directly related to the main study hypotheses and ancillary analyses are also presented and discussed in Appendix S1, Results. Statistical significance was set at $p<.05$. Statistical analyses (except for mediation) were performed using the SAS Studio 3.8 (SAS Institute Inc., Cary, NC).

\subsection{1 | Mediation analysis}

We performed multilevel mediation analysis to test whether the influence of inspiratory threshold loads on RSA is mediated via alterations in the amplitude of SBP variation and/or tidal volume during controlled breathing at $0.1 \mathrm{~Hz}$ (using the CANLAB mediation toolbox in MATLAB; Wager, Davidson, Hughes, Lindquist, \& Ochsner, 2008). All respiratory cycles were included into the mediation analysis, and inspiratory load was considered as a variable with three levels of 0,5 , and $10 \mathrm{cmH}_{2} \mathrm{O}$ (Appendix S1, S2.5.1).

\section{3 | RESULTS}

\section{1 | Participants}

Thirty healthy volunteers participated in the study. One participant was excluded due to an adverse event (dizziness) occurring during the 5-min resting period prior to the main test. One participant could not perform the breathing condition with the load of $10 \mathrm{cmH}_{2} \mathrm{O}$ and reported stronger than moderate dyspnea during the practice phase. However, data of this participant were included in the analyses as she could perform other breathing conditions. Data of 29 subjects were analyzed, including 20 women and 9 men with mean age 21.3 years $\left(S D\right.$ 4.2.) and mean BMI of $22.2 \mathrm{~kg} / \mathrm{m}^{2}(S D 2.5)$. 


\section{2 | Respiratory measures and manipulation check}

Analyses of the respiratory times and tidal volume confirmed that participants could perform controlled breathing as instructed (Table 1, Table S2). This is also visible in the spectral analysis of the respiratory volume (Figure 1a, Figure S2a).

Inspiration time increased with increasing load (all pairwise $p$ values < .05; Table 1, Appendix S1, section S3.2). Tidal volume was higher during breathing with the load of $5 \mathrm{cmH}_{2} \mathrm{O}$ compared to the load of $10 \mathrm{cmH}_{2} \mathrm{O}$ (DLSM $[S E]=141[45] \mathrm{mL}, t(1,28)=3.1, d=0.45, p=.017)$, associated with higher minute ventilation (DLSM $[S E]=0.7[0.2]$ $\mathrm{L} / \mathrm{min}, t(1,28)=2.73, d=0.39, p=.010)$ and lower $\mathrm{EtCO}_{2}$ $(\mathrm{DLSM}[S E]=-0.25[0.04] \%, t(1,28)=-5.18, d=0.52$, $p<.001$; Table 1).

\section{3 | Blood pressure variability}

There was no difference between the breathing conditions in average $\mathrm{SBP}, F(4,28)=0.49, p=.744$, or DBP, $F(4$, $28)=1.99, p=.123$. Spectral analysis showed that BPV was shifted to the LF band during controlled breathing at $0.1 \mathrm{~Hz}$, concentrating around the breathing frequency (Figure 1b, Figure S2b, Table S3). Variability of SBP at the LF band was higher during controlled breathing at $0.1 \mathrm{~Hz}$ with the load of $10 \mathrm{cmH}_{2} \mathrm{O}$ compared to the no load condition (DLSM $[S E]=4.4[0.7], t(1,28)=6.35, d=0.76, p<.001)$ and

T A B L E 1 Means (standard error), [95\% confidence interval] of respiratory variables among the controlled breathing at $0.1 \mathrm{~Hz}$ conditions with and without loads

\begin{tabular}{|llll}
\multicolumn{5}{c}{ Controlled breathing at $\mathbf{0 . 1} \mathbf{~ H z}$} \\
\cline { 2 - 4 } & No load & ITL $\mathbf{5} \mathbf{~ c m ~ H}_{\mathbf{2}} \mathbf{O}$ & ITL 10 cm H $\mathbf{O}$ \\
\hline $\mathrm{T}_{\mathrm{In}}, \mathrm{ms}$ & $3.67(0.04)$ & $3.81(0.05)^{\mathrm{a}}$ & $3.87(0.04)^{\mathrm{a}, \mathrm{b}}$ \\
& {$[3.59,3.76]$} & {$[3.71,3.91]$} & {$[3.78,3.97]$} \\
\hline $\mathrm{T}_{\mathrm{Tot}}, \mathrm{ms}$ & $9.95(0.01)$ & $9.96(0.007)$ & $9.97(0.009)$ \\
& {$[9.92,9.98]$} & {$[9.95,9.98]$} & {$[9.95,9.99]$} \\
\hline $\mathrm{V}_{\mathrm{T}}, \mathrm{mL}$ & $1531(72)$ & $1611(55)$ & $1469(59)^{\mathrm{b}}$ \\
& {$[1381,1680]$} & {$[1497,1724]$} & {$[1348,1591]$} \\
\hline $\mathrm{V}_{\mathrm{E}}, \mathrm{L} / \mathrm{min}$ & $9.2(0.4)$ & $9.7(0.3)$ & $8.9(0.3)$ \\
& {$[8.3,10.1]$} & {$[9.0,10.4]$} & {$[8.1,9.7]$} \\
\hline $\mathrm{EtCO}_{2}, \%$ & $4.9(0.09)$ & $4.8(0.08)$ & $5.1(0.09)^{\mathrm{b}}$ \\
& {$[4.7,5.1]$} & {$[4.6,5.0]$} & {$[4.9,5.3]$} \\
\hline
\end{tabular}

Abbreviations: ITL, inspiratory threshold load; $\mathrm{T}_{\mathrm{In}}$, inspiration time; $\mathrm{T}_{\mathrm{Tot}}$, total respiratory time; $\mathrm{V}_{\mathrm{T}}$, tidal volume; $\mathrm{V}_{\mathrm{E}}$, minute ventilation; $\mathrm{EtCO}_{2}$, end-tidal carbon dioxide.

Note. Pairwise comparison with significant difference $(p<.05)$ compared with abreathing at $0.1 \mathrm{~Hz}$ without load,

breathing at $0.1 \mathrm{~Hz}$ with the load of $5 \mathrm{cmH}_{2} \mathrm{O}$ compared to breathing with the load of $5 \mathrm{cmH}_{2} \mathrm{O}$ (DLSM $[S E]=2.6[0.5], t(1,28)=4.89, d=0.43, p<.001)$; it was also higher during breathing with the load of $5 \mathrm{cmH}_{2} \mathrm{O}$ compared to the no load condition (DLSM $[S E]=1.8[0.6]$, $t(1,28)=3.01, d=0.31, p=.010)$; Table 2 .

Similarly, the amplitude of SBP variation during respiratory cycles was higher during controlled breathing at $0.1 \mathrm{~Hz}$ with the load of $10 \mathrm{cmH}_{2} \mathrm{O}$ compared to the no load condition $(\mathrm{DLSM}[S E]=8.9[1.1] \mathrm{mmHg}, t(1,28)=7.80$, $d=1.10, p<.001)$ and compared to breathing with the load of $5 \mathrm{cmH}_{2} \mathrm{O}$ (DLSM $[S E]=5.4[0.8] \mathrm{mmHg}, t(1,28)=6.49$, $d=0.63, p<.001)$; it was also higher during breathing with the load of $5 \mathrm{cmH}_{2} \mathrm{O}$ compared to the no load condition $(\mathrm{DLSM}[S E]=3.5[0.8] \mathrm{mmHg}, t(1,28)=4.28, d=0.47$, $p<.001)$. Figure 2 illustrates how SBP and RR interval swing along the respiratory cycle during controlled breathing at $0.1 \mathrm{~Hz}$ as a function of inspiratory load.

(a) Volume

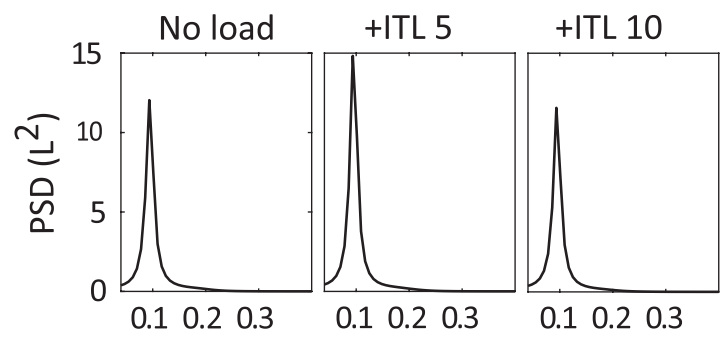

(b) SBP

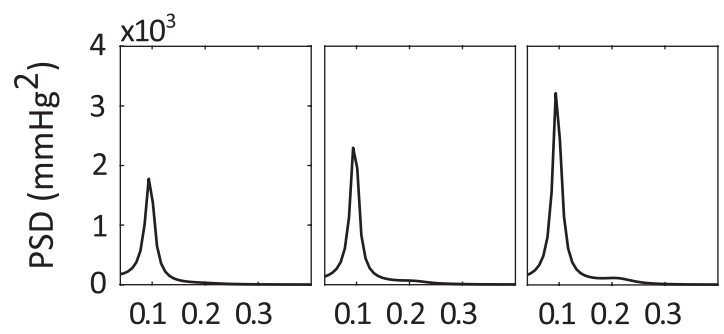

(c) RRI

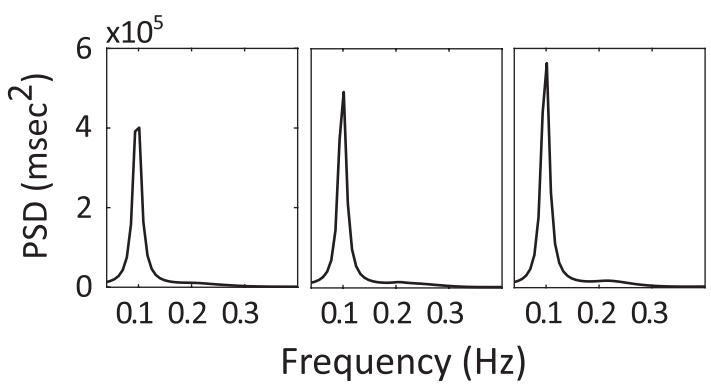

F I G URE 1 Power spectral density (PSD) of (a) respiratory volume, (b) systolic blood pressure (SBP), and (c) RR interval during controlled breathing at $0.1 \mathrm{~Hz}$ without load and with inspiratory threshold loads (ITL) of $5 \mathrm{cmH}_{2} \mathrm{O}$ (+ITL 5) and $10 \mathrm{cmH}_{2} \mathrm{O}$ (+ITL 10). Data reflects averages across all participants 


\begin{tabular}{|c|c|c|c|}
\hline & \multicolumn{3}{|c|}{ Controlled breathing at $0.1 \mathrm{~Hz}$} \\
\hline & No load & ITL $5 \mathrm{cmH}_{2} \mathrm{O}$ & ITL $10 \mathrm{cmH}_{2} \mathrm{O}$ \\
\hline \multicolumn{4}{|l|}{ BPV indices } \\
\hline \multirow[t]{2}{*}{ Mean SBP, mmHg } & $111.9(2.5)$ & $109.8(2.5)$ & $110.9(2.6)$ \\
\hline & {$[106.6,117.2]$} & {$[104.5,115.1]$} & {$[105.5,116.2]$} \\
\hline \multirow[t]{2}{*}{ Mean DBP, $\mathrm{mmHg}$} & $73.1(1.6)$ & $71.5(1.8)$ & $72.1(1.6)$ \\
\hline & {$[69.8,76.5]$} & {$[67.8,75.2]$} & {$[68.7,75.6]$} \\
\hline \multirow[t]{2}{*}{ LFabs* } & $31.7(1.0)$ & $33.5(1.0)^{\mathrm{a}}$ & $36.2(1.1)^{\mathrm{a}, \mathrm{b}}$ \\
\hline & {$[29.6,33.8]$} & {$[31.3,35.7]$} & {$[33.8,38.5]$} \\
\hline \multirow[t]{2}{*}{$\mathrm{rBPV}, \mathrm{mmHg}$} & $21.5(1.2)$ & $25.0(1.4)^{\mathrm{a}}$ & $30.5(1.6)^{\mathrm{a}, \mathrm{b}}$ \\
\hline & {$[18.9,24.2]$} & {$[22.0,28.1]$} & {$[27.0,33.9]$} \\
\hline \multicolumn{4}{|l|}{ HRV indices } \\
\hline \multirow[t]{2}{*}{ Mean RR interval, ms } & $838(21)$ & $840(20)$ & $839(20)$ \\
\hline & {$[795,882]$} & {$[797,884]$} & {$[797,881]$} \\
\hline \multirow[t]{2}{*}{ RMSSD, ms } & $77(5)$ & $88(6)^{\mathrm{a}}$ & $94(7)^{\mathrm{a}}$ \\
\hline & {$[65,89]$} & {$[74,102]$} & {$[79,109]$} \\
\hline \multirow[t]{2}{*}{ LFabs* } & $129.6(4.5)$ & $132.1(4.4)$ & $136.0(4.7)$ \\
\hline & {$[120.3,138.8]$} & {$[123.0,141.3]$} & {$[126.3,145.6]$} \\
\hline \multirow[t]{2}{*}{$\mathrm{RSA}, \mathrm{ms}$} & $313(19)$ & $337(20)$ & $356(21)^{\mathrm{a}, \mathrm{b}}$ \\
\hline & {$[273,353]$} & {$[296,379]$} & {$[313,400]$} \\
\hline \multirow[t]{2}{*}{$\mathrm{BRS}, \mathrm{ms} / \mathrm{mmHg}$} & $21.6(1.7)$ & $21.5(1.8)$ & $21.6(1.9)$ \\
\hline & {$[17.9,25.3]$} & {$[17.7,25.3]$} & {$[17.7,25.6]$} \\
\hline
\end{tabular}

T A B LE 2 Means (standard error), [95\% confidence interval] of blood pressure variability, heart rate variability, and baroreflex indexes among the controlled breathing at $0.1 \mathrm{~Hz}$ conditions with and without loads

Abbreviations: BPV, blood pressure variability; BRS, baroreflex sensitivity; DBP, diastolic blood pressure; HRV, heart rate variability; ITL, inspiratory threshold load; LFabs, low frequency absolute power; rBPV, amplitude of systolic blood pressure variation in respiratory cycles; RMSSD, root mean square of the successive differences [in RR intervals]; RSA, respiratory sinus arrhythmia; SBP, systolic blood pressure.

Note. Pairwise comparison with significant difference $(p<.05)$ compared with

abreathing at $0.1 \mathrm{~Hz}$ without load,

breathing at $0.1 \mathrm{~Hz}$ with the load of $5 \mathrm{cmH}_{2} \mathrm{O}$.

*Box-Cox transformed.

\section{4 $\quad$ Heart rate variability}

Spectral analysis showed that HRV was shifted to the LF band during controlled breathing at $0.1 \mathrm{~Hz}$, concentrating around the breathing frequency (Figure 1c, Figure S2c, Table S3). There was a nonsignificant difference between controlled breathing at $0.1 \mathrm{~Hz}$ with the load of $10 \mathrm{cmH}_{2} \mathrm{O}$ and the no load condition in LF-HRV (DLSM $[S E]=6.3$ [2.7], $t(1,28)=2.30, d=0.25, p=.087$; Table 2).

Compared to controlled breathing at $0.1 \mathrm{~Hz}$ without load, RMSSD was higher during breathing with the load of 5 $\mathrm{cmH}_{2} \mathrm{O}$ (DLSM $[S E]=10[3] \mathrm{ms}, t(1,28)=2.99, d=0.30$, $p=.017)$ and higher during breathing with the load of 10 $\mathrm{cmH}_{2} \mathrm{O}(\mathrm{DLSM}[S E]=16[4] \mathrm{ms}, t(1,28)=3.77, d=0.46$, $p=.003$ ). The difference in RMSSD between breathing with the load of 5 and $10 \mathrm{cmH}_{2} \mathrm{O}$ was not significant (DLSM $[S E]=6[3] \mathrm{ms}, t(1,28)=2.05, d=0.16, p=.100$; Table 2).

RSA was higher during controlled breathing at $0.1 \mathrm{~Hz}$ with the load of $10 \mathrm{cmH}_{2} \mathrm{O}$ compared to the no load condition $(\mathrm{DLSM}[S E]=43[14] \mathrm{ms}, t(1,28)=3.01, d=0.39, p=.016)$.
Differences between breathing with the load of $5 \mathrm{cmH}_{2} \mathrm{O}$ and the no load condition (DLSM $[S E]=24[11] \mathrm{ms}, t(1,28)=2.05$, $d=0.22, p=.099)$ and between breathing with the load of 5 and $10 \mathrm{cmH}_{2} \mathrm{O}$ (DLSM $[S E]=19$ [9] $\mathrm{ms}, t(1,28)=1.96$, $d=0.17, p=.099$ ) were not significant (Table 2).

\section{5 | Baroreflex sensitivity}

There was no difference between the controlled breathing at $0.1 \mathrm{~Hz}$ conditions in BRS (all pairwise $p$ values $>.999$, Table 2, Table S4).

\section{6 | Is the effect of inspiratory threshold load on RSA mediated by the changes in BPV and/or tidal volume?}

The magnitude of load (no load and loads of 5 and $10 \mathrm{cmH}_{2} \mathrm{O}$ ) was correlated with RSA (coefficient $=18.58, p=.008$ ). This association was no longer significant after controlling for the amplitude of SBP variation during respiratory cycles 


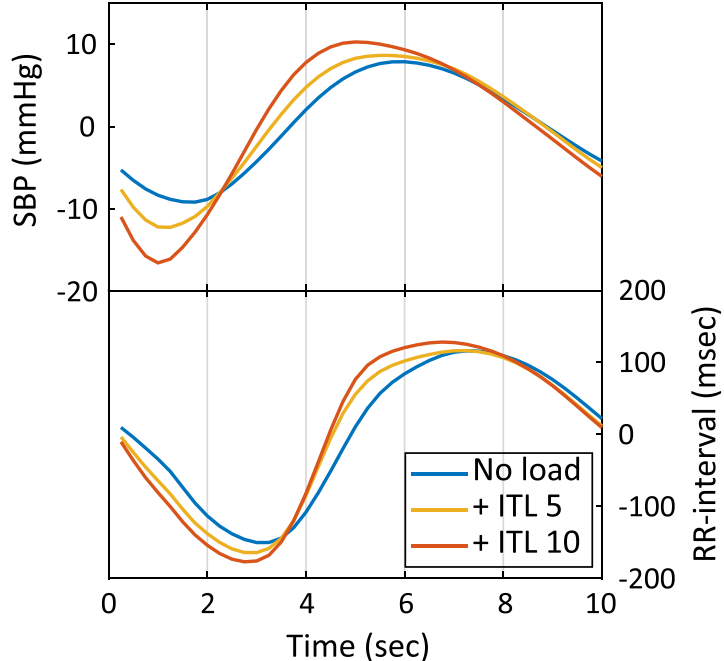

F I G U RE 2 Pattern analysis of systolic blood pressure (SBP) and RR interval during respiratory cycle in controlled breathing at $0.1 \mathrm{~Hz}$ without load and with inspiratory threshold loads (ITL) of $5 \mathrm{cmH}_{2} \mathrm{O}$ (+ITL 5) and $10 \mathrm{cmH}_{2} \mathrm{O}$ (+ITL 10); SBP has more decrease during inspiration and subsequently increases up to a higher level at the beginning of expiration during controlled breathing at $0.1 \mathrm{~Hz}$ with load compared to breathing without load, and this response follows the magnitude of the load. RR interval follows the changes in SBP: lower during inspiration and higher during expiration during controlled breathing at $0.1 \mathrm{~Hz}$ with load compared to breathing without load. Changes from nadir to peak also become steeper for both SBP and $\mathrm{RR}$ interval in response to load. The delay between changes in SBP and RR interval indicates the baroreflex latency and time lag (Sin et al., 2010). Data are averaged across all respiratory cycles for each condition/participant and then averaged across all participants (coefficient $=-0.42, p=.922$, Figure $3 b$ ) but remained significant after controlling for tidal volume (coefficient $=20.18$, $p=.006$, Figure 3c). This result did not change after including covariates (inspiration time, tidal volume, $\mathrm{EtCO}_{2}$ ) into the model (Appendix S1, section S3.6.).

Heart rate can influence SBP via the feed-forward mechanisms; reduced heart rate increases ventricular filling and preload, which in turn increases stroke volume (Schulz et al., 2013). Therefore, we repeated the mediation analysis with RSA as the possible mediator and the amplitude of SBP variation during respiratory cycles as the dependent variable. The association of load with the amplitude of SBP variation remained significant (coefficient $=3.49, p<.001$ ) after controlling for RSA (Figure 3d).

\section{7 | Dyspnea and emotional valence and arousal}

Compared to controlled breathing without load, self-reported dyspnea was higher during breathing with loads of 5 $(\mathrm{DLSM}[S E]=1.0[0.1], t(1,28)=6.79, d=1.13, p<.001)$ and $10 \mathrm{cmH}_{2} \mathrm{O}(\mathrm{DLSM}[S E]=1.6[0.2], t(1,28)=7.41$, $d=1.69, p<.001)$. The difference between the load of 5 and $10 \mathrm{cmH}_{2} \mathrm{O}$ was not significant (DLSM [SE] $=0.6$ [0.2], $t(1,28)=2.55, d=0.56, p=.066$; Figure 4a). Participants rated breathing with the load of $10 \mathrm{cmH}_{2} \mathrm{O}$ as less pleasant than with the load of $5 \mathrm{cmH}_{2} \mathrm{O}$ (DLSM [SE] $=-.5$ [0.2], $t(1,28)=-2.93, d=0.39, p=.049)$ and the no load conditions (DLSM $[S E]=-.6[0.2], t(1,28)=-2.96, d=0.44$, $p=.049)$, Figure 4b. (a)

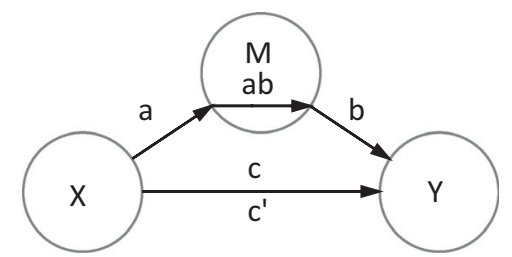

(c)

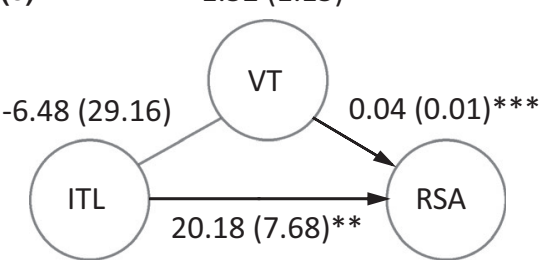

(b)

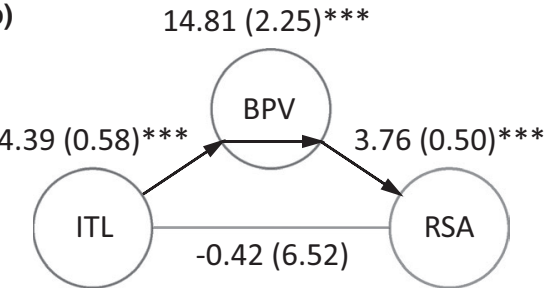

(d)

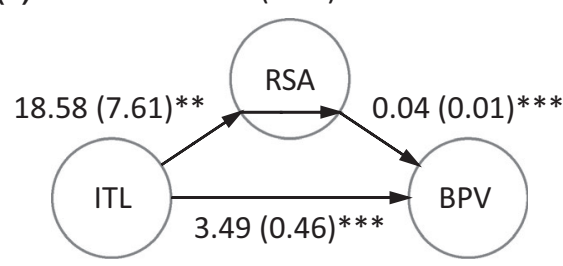

F I G U R E 3 Multilevel mediation analysis. X, independent variable; Y, dependent variable; M, mediator; a, X => M relationship; b, M => Y relationship; c', $\mathrm{X}=>\mathrm{Y}$ unmediated relationship (residual); c, $\mathrm{X}=>\mathrm{Y}$ total relationship; ab, $\mathrm{X}=>\mathrm{Y}$ mediated by $\mathrm{M}$ (model 3a). Examining the effect of inspiratory threshold load (ITL) on respiratory sinus arrhythmia (RSA) having the amplitude of systolic blood pressure variation during respiratory cycles $(\mathrm{BPV}$, model $3 \mathrm{~b})$ or tidal volume $\left(\mathrm{V}_{\mathrm{T}}\right.$, model $\left.3 \mathrm{c}\right)$ as possible mediators. In model 3d, the effect of ITL on BPV is examined having RSA as possible mediator. Data are coefficients (standard error). Arrows indicate significant association. $* * p<.01 ; * * * p<.001$ 
(a) Dyspnea

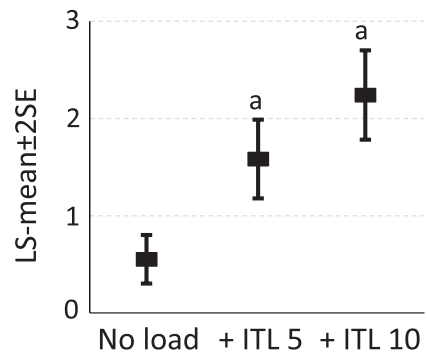

(b) Valence

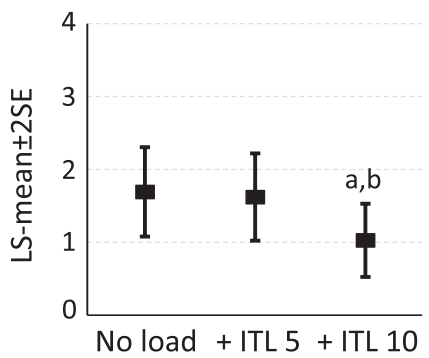

(c) Arousal

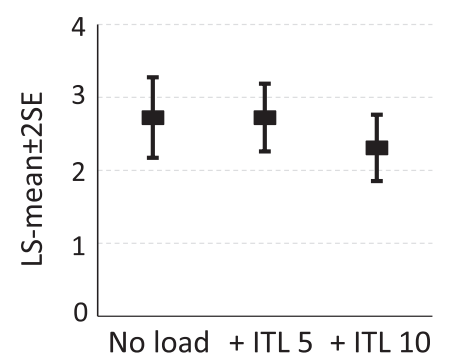

F I G URE 4 Comparison of self-reported (a) dyspnea, (b) emotional valence (pleasant vs. unpleasant), and (c) emotional arousal (calm vs. excited) among the controlled breathing at $0.1 \mathrm{~Hz}$ conditions without load and with inspiratory threshold loads (ITL) of $5 \mathrm{cmH}_{2} \mathrm{O}(+\mathrm{ITL} 5)$ and 10 $\mathrm{cmH}_{2} \mathrm{O}$ (+ITL 10). Data are presented as least squares means (LS-means) \pm 2 standard error (SE). The BORG scale is presented up to moderate level (score 3), and the Manikin scales are presented from neutral level (score 0 ) to extremely pleasant (score 4) and extremely calm (score 4)

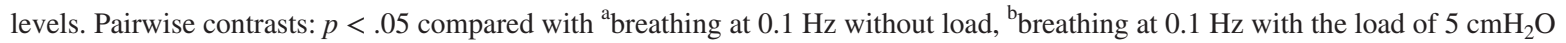

\section{4 | DISCUSSION}

In this experiment we evaluated the influence of inspiratory threshold loading during controlled breathing at $0.1 \mathrm{~Hz}$ on cardiorespiratory responses. The results confirmed our hypothesis that an inspiratory threshold load during controlled breathing at $0.1 \mathrm{~Hz}$ would further increase RSA and that this effect seems to be mediated by larger SBP swings along the respiratory cycle. These results suggest that stronger stimulation of the arterial baroreceptors by applying the inspiratory load during controlled breathing at $0.1 \mathrm{~Hz}$ increased cardiac vagal modulation.

The increase in RSA during instructed SDB has been reported previously (e.g., Cooke et al., 1998; Pitzalis, 1998; Sin et al., 2010), though the underlying mechanisms are not completely understood. A recent study using pharmacological autonomic blockade (i.e., with antimuscarinic, anticholinergic, and beta blocker) supports the idea that the increase in RSA during SDB reflects an increase in cardiac vagal modulation (Kromenacker et al., 2018). Sensory afferents from the pulmonary stretch receptors, chemoreceptors, and arterial baroreceptors terminate in the nucleus tractus solitarius which controls the autonomic outflow via nucleus ambiguus and caudal ventrolateral medulla (Kubin, Alheid, Zuperku, \& McCrimmon, 2006; Pilowsky \& Goodchild, 2002). Findings from studies on lung transplant patients (i.e., with denervated lung) suggest that vagal afferent signals from the pulmonary stretch receptors may contribute to RSA during breathing at a normal frequency (Fontolliet et al., 2018; Khayat, Przybylowski, Meyer, Skatrud, \& Morgan, 2004; Taha, Simon, Dempsey, Skatrud, \& Iber, 1995). However, whether and to what extent such neural modulation contributes to the observed increase in RSA during breathing at a low $(\sim 0.1 \mathrm{~Hz})$ frequency is not clear. Cooke et al. (1998) compared controlled breathing at different breathing frequencies (including $0.1 \mathrm{~Hz}$ ) with and without controlling tidal volume. They found a significant decrease in HRV at a frequency of $0.1 \mathrm{~Hz}$ when tidal volume was controlled via visual feedback (vs. uncontrolled tidal volume), while the variability of SBP was not altered. Having different inspiratory threshold loads, it was not feasible in our study to manipulate/control tidal volume across the breathing conditions. According to the mediation analysis, the effect of loads on RSA was not dependent on tidal volume. However, tidal volume was associated with RSA independently from loading. These results suggest a contribution of vagal afferent signals from the pulmonary stretch receptors to RSA during controlled breathing at $0.1 \mathrm{~Hz}$.

Although there is an ongoing debate on the role of the baroreflex in RSA during breathing at normal frequency (Eckberg, 2009), it is generally accepted that afferent signals from the arterial baroreceptors contribute to RSA during breathing at low $(\sim 0.1 \mathrm{~Hz})$ frequency (Stankovski et al., 2013). Slow, deep breathing increases the amplitude of blood pressure swings during respiratory cycle. This is largely due to the mechanical effects of respiration on the left and right ventricle stroke volume (Elstad, O'Callaghan, Smith, Ben-Tal, $\&$ Ramchandra, 2018). The increase in blood pressure swing leads to increased baroreceptor stimulation, reflected by the increase in RSA, and other HRV indexes (Horsman et al., 2015; Stankovski et al., 2013). Other methods of generating low frequency oscillation in blood pressure (e.g., lower body negative pressure) are similarly able to increase cardiovagal response, suggesting an increase in baroreflex gain at low frequencies (i.e., $\sim 0.1 \mathrm{~Hz}$; Horsman et al., 2015; Stankovski et al., 2013). The observed delay between changes in SBP and RR-interval time series in the pattern analysis in our study (Figure 3) is in line with the baroreflex latency and time lag (Sin et al., 2010). Our results show that adding an inspiratory threshold load during controlled breathing at $0.1 \mathrm{~Hz}$ can augment low frequency oscillations in blood pressure, resulting in increased baroreceptor stimulation and modulation of the cardiac vagal outflow, as was reflected by the increased RSA.

Cardiovagal baroreflex sensitivity has been shown by several studies to increase during instructed SDB (Frederiks et al., 2000; Joseph et al., 2005; Rosengård-Bärlund et al., 2011; 
Tzeng, Sin, Lucas, \& Ainslie, 2009; Wang, Kuo, Lai, Chu, \& Yang, 2013). In our study, baroreflex sensitivity was not further increased by using the loads, which may be due either to a ceiling effect or to the frequency-dependent nature of the baroreflex (Horsman et al., 2015). However, with the baroreflex operating within a larger range of SBP fluctuations, application of inspiratory threshold loads during controlled breathing at $0.1 \mathrm{~Hz}$ may improve baroreflex function when practiced over a longer period (see section 4.1), this possibility warrants further investigation.

We did not observe any acute effect of inspiratory threshold load during controlled breathing at $0.1 \mathrm{~Hz}$ on the average SBP or DBP. Also, the average RR interval did not change during the breathing conditions, suggesting no acute effect on cardiac vagal "tone." These findings highlight the distinction between the respiratory modulation of cardiac vagal outflow (i.e., RSA) and cardiac vagal tonic activity (Farmer, Dutschmann, Paton, Pickering, \& McAllen, 2016; Grossman $\&$ Taylor, 2007). Patients with hypertension have higher sympathetic and lower parasympathetic activity at rest compared with healthy controls (Mancia \& Grassi, 2014). A number of studies have shown that SDB can acutely decrease blood pressure in cardiac patients, and these effects have been attributed to increased baroreflex sensitivity/baroreceptor stimulation and decreased sympathetic activity (Bernardi et al., 2002; Fonkoue et al., 2018; Harada et al., 2014; Joseph et al., 2005; Oneda, Ortega, Gusmão, Araújo, \& Mion, 2010). Whether or not applying inspiratory threshold load during controlled breathing at $0.1 \mathrm{~Hz}$ can acutely decrease blood pressure/heart rate needs further investigation in these patients.

SDB has been shown to decrease arousal under threatening/stress situations (Cappo \& Holmes, 1984; McCaul, Solomon, \& Holmes, 1979). In our study, self-reported measures of emotional valence and (nonsignificantly) arousal were higher with an inspiratory load of $10 \mathrm{cmH}_{2} \mathrm{O}$ during controlled breathing at $0.1 \mathrm{~Hz}$ compared to the no load condition. Therefore, applying an inspiratory load may not be beneficial in conditions where emotional responses to the breathing exercise (e.g., relaxation response) are targeted as possible mechanisms of action. It must be noted that the psycho-physiological responses to controlled breathing at $0.1 \mathrm{~Hz}$ with loads may depend, among others, on the studied population (patients with different motivations compared to healthy controls) and the study context (resting vs. arousal state). The effects of applying inspiratory threshold load during controlled breathing at $0.1 \mathrm{~Hz}$ on emotional responses need further investigation in patient populations (e.g., in hypertension and pain).

\section{1 | Clinical applications of slow, deep breathing with inspiratory loading}

Few studies have evaluated the effects of long-term SDB practice on cardiovascular responses in a nonpatient population. Lehrer et al. (2003) have reported an increase in resting baroreflex gain (but not mean RR interval) after 10 weekly sessions of HRV biofeedback, while resting breathing frequency was not altered. Another study evaluating the influence of 30-day SDB practice on cardiac vagal activity has found an increase in the morning and night HRV in the HF band (but not mean RR interval), also without alteration in the corresponding breathing frequencies (Laborde, Hosang, Mosley, \& Dosseville, 2019). Only one study has reported a reduction in resting heart rate (suggesting an increase in cardiac vagal tone) after long-term SDB paractice (Pal, Velkumary, \& Madanmohan, 2004). Pal et al. also found an increase in RSA in response to a deep breathing test after 3 months of regular SDB practice. Although this suggests an increase in baroreflex sensitivity (Arica, Firat Ince, Bozkurt, Tewfik, \& Birand, 2011), this finding should be interpreted cautiously, since breathing frequency was not controlled in the deep breathing test in this study. Pal et al. (2004) also report on a reduced heart rate in rapid response to standing, which suggests a decrease in sympathetic activity (Stewart, 2012). Overall, these results support the idea that the regular practice of SDB may, in the longer term, generate lasting effects on baroreflex function and cardiac autonomic control, suggesting alterations at the neural level (Lehrer et al., 2003). However, considering the limited and inconsistent evidence available, further long-term studies are required before a clear conclusion can be made in this regard.

Controlled clinical trials in patients with hypertension have shown reductions in resting blood pressure and heart rate by long-term practice of SDB (Zou et al., 2017). Improvement in baroreflex sensitivity, increased parasympathetic modulation, and decreased sympathetic tone are proposed as possible underlying mechanisms (Cernes \& Zimlichman, 2015; Modesti, Ferrari, Bazzini, \& Boddi, 2015). In a recent clinical trial, hypertensive patients practiced controlled breathing at $0.1 \mathrm{~Hz}$ with or without inspiratory load of $20 \mathrm{cmH}_{2} \mathrm{O}$ for 8 weeks. Although blood pressure and heart rate decreased in both groups, a greater reduction in blood pressure (and a trend for heart rate) was observed for the group practicing with the inspiratory load (Jones, Sangthong, \& Pachirat, 2010). These results, in addition to the findings of our experiment, suggest that applying inspiratory threshold load during controlled breathing at $0.1 \mathrm{~Hz}$ may enhance the effect of this breathing exercise on baroreflex function and cardiac vagal control when practiced for several weeks. Since baroreflex sensitivity was not measured in the previous clinical trial (Jones et al., 2010), whether adding load to controlled breathing at $0.1 \mathrm{~Hz}$ can improve baroreflex function in the long term is not clear and needs further investigation.

Another potential clinical application of SDB is in pain management, as experimental studies have provided promising results in this regard (Jafari et al., 2017). Stimulation of the arterial baroreceptors and autonomic responses to 
SDB are proposed, among others, as possible underlying mechanisms (Jafari et al., 2017). Botha et al. (2015) found that SDB (at $0.1 \mathrm{~Hz}$ ) can prevent development of esophageal pain hypersensitivity and that this effect is mediated by the increased parasympathetic activity in response to SDB, as the effect was blocked after administration of atropine. Stimulation of the arterial baroreceptors has antinociceptive effects (Ditto, Lewkowski, Rainville, \& Duncan, 2009; Reyes Del Paso, Montoro, Muñóz Ladrón de Guevara, Duschek, \& Jennings, 2014; Ring, Edwards, \& Kavussanu, 2008). Studies have also shown decreased baroreflex sensitivity and cardiac vagal tone in patients with chronic pain (Chung et al., 2008). Preoperative baroreflex sensitivity and cardiac parasympathetic activity have been shown to predict development of postoperative pain (Nielsen et al., 2015). Daily practice of SDB can improve baroreflex sensitivity and vagal tone, which in turn may contribute to pain inhibition. Although applying a load during controlled breathing at $0.1 \mathrm{~Hz}$ did not further increase the baroreflex sensitivity in the short term in our study, it was associated with stronger baroreceptors stimulation and increased cardiac vagal modulation, which may have stronger pain inhibitory effects. These potential benefits warrant investigation in future studies.

\section{2 | Possible adverse effects of SDB}

In our study, one participant experienced dizziness during the resting period prior to the main test; therefore, this is not likely to be due to the intervention. One concern during controlled/deep breathing exercises is hyperventilation (Szulczewski \& Rynkiewicz, 2018). In our study, the load of $5 \mathrm{cmH}_{2} \mathrm{O}$, but not $10 \mathrm{cmH}_{2} \mathrm{O}$, was associated with lower $\mathrm{EtCO}_{2}$ compared to the no load condition. Therefore, hyperventilation should be monitored during training and prevented by instructions (Szulczewski, 2019). The low-to-moderate levels of dyspnea reported by our participants with the load of $10 \mathrm{cmH}_{2} \mathrm{O}$ may be reduced by decreasing the duration of the exercise and by more frequent practice over time. Studies in hypertension patients using long-term practice with loads of 18-20 $\mathrm{cmH}_{2} \mathrm{O}$ have reported good compliance without any specific adverse events (Jones et al., 2010; Sangthong, Ubolsakka-Jones, Pachirat, \& Jones, 2016; Ubolsakka-Jones, Sangthong, Khrisanapant, \& Jones, 2017).

\section{3 | Study limitations}

Our study has a number of limitations. Participants were mostly women aged 18 to 36 years. Considering the effects of age and gender on baroreflex function and cardiac vagal control (Laitinen et al., 1998), replication of this study in a relatively older population and including both genders with larger sample size is warranted. Although we applied mediation analysis, precise investigation of the mechanisms of the increased cardiac vagal modulation in response to controlled breathing at $0.1 \mathrm{~Hz}$ and additional effects of inspiratory threshold load requires selective blockade of the possible pathways, though this is hardly possible in human experimental studies.

\section{4 $\mid$ Conclusion}

Applying small inspiratory threshold loads during controlled breathing at $0.1 \mathrm{~Hz}$ enhances the effects of this breathing exercise on cardiac vagal modulation, likely by stronger stimulation of the arterial baroreceptors because of greater blood pressure swings along the respiratory cycle. This technique may enhance the benefits of controlled breathing at $0.1 \mathrm{~Hz}$ on baroreflex function and cardiac vagal control if practiced long term and warrants further investigation both in healthy persons and in patients with pain and hypertension.

\section{ACKNOWLEDGMENTS}

The authors would like to thank Mathijs Franssen and Jeroen Clarysse (Health Psychology Research Group, KU Leuven) for providing technical support during this study.

\section{ORCID}

Ali Gholamrezaei iD https://orcid.org/0000-0001-8674-450X

Ilse Van Diest iD https://orcid.org/0000-0002-0048-774X

\section{REFERENCES}

Arica, S., Firat Ince, N., Bozkurt, A., Tewfik, A. H., \& Birand, A. (2011). Prediction of pharmacologically induced baroreflex sensitivity from local time and frequency domain indices of R-R interval and systolic blood pressure signals obtained during deep breathing. Computers in Biology and Medicine, 41, 442-448. https://doi. org/10.1016/j.compbiomed.2011.04.006

Bernardi, L., Porta, C., Spicuzza, L., Bellwon, J., Spadacini, G., Frey, A. W., ... Tramarin, R. (2002). Slow breathing increases arterial baroreflex sensitivity in patients with chronic heart failure. Circulation, 105(2), 143-145. https://doi.org/10.1161/ hc0202.103311

Bjelland, I., Dahl, A. A., Haug, T. T., \& Neckelmann, D. (2002). The validity of the Hospital Anxiety and Depression Scale. Journal of Psychosomatic Research, 52(2), 69-77. https://doi.org/10.1016/ S0022-3999(01)00296-3

Borg, G. A. (1982). Psychophysical bases of perceived exertion. Medicine and Science in Sports and Exercise, 14(5), 377-381. https://doi.org/10.1249/00005768-198205000-00012

Botha, C., Farmer, A. D., Nilsson, M., Brock, C., Gavrila, A. D., Drewes, A. M., ... Aziz, Q. (2015). Preliminary report: Modulation of parasympathetic nervous system tone influences oesophageal pain hypersensitivity. Gut, 64(4), 611-617. https://doi.org/10.1136/ gutjnl-2013-306698 
Bradley, M., \& Lang, P. J. (1994). Measuring emotion: The self-assessment semantic differential Manikin and the semantic differential. Journal of Behavior Therapy and Experimental Psychiatry, 25(1), 49-59. https://doi.org/10.1016/0005-7916(94)90063-9

Calabrese, P., Perrault, H., Dinh, T. P., Eberhard, A., \& Benchetrit, G. (2000). Cardiorespiratory interactions during resistive load breathing. American Journal of Physiology-Regulatory, Integrative and Comparative Physiology, 279(6), R2208-R2213. https://doi. org/10.1152/ajpregu.2000.279.6.R2208

Cappo, B. M., \& Holmes, D. S. (1984). The utility of prolonged respiratory exhalation for reducing physiological and psychological arousal in non-threatening and threatening situations. Journal of Psychosomatic Research, 28(4), 265-273. https://doi. org/10.1016/0022-3999(84)90048-5

Cernes, R., \& Zimlichman, R. (2015). RESPeRATE: The role of paced breathing in hypertension treatment. Journal of the American Society of Hypertension: JASH, 9(1), 38-47. https://doi.org/10.1016/j. jash.2014.10.002

Chung, O. Y., Bruehl, S., Diedrich, L., Diedrich, A., Chont, M., \& Robertson, D. (2008). Baroreflex sensitivity associated hypoalgesia in healthy states is altered by chronic pain. Pain, 138(1), 87-97. https://doi.org/10.1016/j.pain.2007.11.011

Convertino, V. A., Ratliff, D. A., Ryan, K. L., Cooke, W. H., Doerr, D. F., Ludwig, D. A., ... Lurie, K. G. (2004). Effects of inspiratory impedance on the carotid-cardiac baroreflex response in humans. Clinical Autonomic Research, 14(4), 240-248. https://doi. org/10.1007/s10286-004-0180-4

Convertino, V. A., Ratliff, D. A., Ryan, K. L., Doerr, D. F., Ludwig, D. A., Muniz, G. W., ... Idris, A. H. (2004). Hemodynamics associated with breathing through an inspiratory impedance threshold device in human volunteers. Critical Care Medicine, 32(9 Suppl), S381-S386. https://doi.org/10.1097/01.CCM.0000134348.69165.15

Cooke, W. H., Cox, J. F., Diedrich, A. M., Taylor, J. A., Beightol, L. A., Ames, J. E., ... Eckberg, D. L. (1998). Controlled breathing protocols probe human autonomic cardiovascular rhythms. American Journal of Physiology-Heart and Circulatory Physiology, 274(2), H709-H718. https://doi.org/10.1152/ajpheart.1998.274.2.H709

Cooke, W. H., Lurie, K. G., Rohrer, M. J., \& Convertino, V. A. (2006). Human autonomic and cerebrovascular responses to inspiratory impedance. Journal of Trauma, 60(6), 1275-1283. https://doi. org/10.1097/01.ta.0000221348.82115.a2

Davies, L. C., Francis, D. P., Scott, A. C., Ponikowski, P., Piepoli, M., \& Coats, A. J. (2001). Effect of altering conditions of the sequence method on baroreflex sensitivity. Journal of Hypertension, 19(7), 1279-1287. https://doi.org/10.1097/00004872-200107000-00013

de Geus, E. J. C., Gianaros, P. J., Brindle, R. C., Jennings, J. R., \& Berntson, G. G. (2019). Should heart rate variability be "corrected" for heart rate? Biological, quantitative, and interpretive considerations. Psychophysiology, 56(2), e13287. https://doi.org/10.1111/psyp.13287

Ditto, B., Lewkowski, M. D., Rainville, P., \& Duncan, G. H. (2009). Effects of cardiopulmonary baroreceptor activation on pain may be moderated by risk for hypertension. Biological Psychology, 82(2), 211-213. https://doi.org/10.1016/j.biopsycho.2009.07.009

Eckberg, D. (2009). Point: counterpoint: Respiratory sinus arrhythmia is due to a central mechanism vs. respiratory sinus arrhythmia is due to the baroreflex mechanism. Journal of Applied Physiology, 106, 1740-1744. https://doi.org/10.1152/japplphysiol.91107.2008

Elstad, M., O’Callaghan, E. L., Smith, A. J., Ben-Tal, A., \& Ramchandra, R. (2018). Cardiorespiratory interactions in humans and animals:
Rhythms for life. American Journal of Physiology-Heart and Circulatory Physiology, 315(1), H6-H17. https://doi.org/10.1152/ ajpheart.00701.2017

Farmer, D. G. S., Dutschmann, M., Paton, J. F. R., Pickering, A. E., \& McAllen, R. M. (2016). Brainstem sources of cardiac vagal tone and respiratory sinus arrhythmia. Journal of Physiology, 594(24), 7249-7265. https://doi.org/10.1113/JP273164

Fonkoue, I. T., Marvar, P. J., Norrholm, S. D., Kankam, M. L., Li, Y., DaCosta, D., ... Park, J. (2018). Acute effects of device-guided slow breathing on sympathetic nerve activity and baroreflex sensitivity in posttraumatic stress disorder. American Journal of Physiology. Heart and Circulatory Physiology, 29(6), 386-391. https://doi. org/10.1152/ajpheart.00098.2018

Fontolliet, T., Gianella, P., Pichot, V., Barthélémy, J.-C., Gasche-Soccal, P., Ferretti, G., \& Lador, F. (2018). Heart rate variability and baroreflex sensitivity in bilateral lung transplant recipients. Clinical Physiology and Functional Imaging, 38(5), 872-880. https://doi. org/10.1111/cpf.12499

Frederiks, J., Swenne, C. A., TenVoorde, B. J., Honzíkovaá, N., Levert, J. V., Maan, A. C., ... Bruschke, A. V. G. (2000). The importance of high-frequency paced breathing in spectral baroreflex sensitivity assessment. Journal of Hypertension, 18(11), 1635-1644. https://doi.org/10.1097/00004872-200018110-00015

Gosselink, R., Wagenaar, R. C., \& Decramer, M. (1996). Reliability of a commercially available threshold loading device in healthy subjects and in patients with chronic obstructive pulmonary disease. Thorax, 51(6), 601-605. https://doi.org/10.1136/thx.51.6.601

Grossman, P., \& Taylor, E. W. (2007). Toward understanding respiratory sinus arrhythmia: Relations to cardiac vagal tone, evolution and biobehavioral functions. Biological Psychology, 74(2), 263-285. https://doi.org/10.1016/j.biopsycho.2005.11.014

Harada, D., Asanoi, H., Takagawa, J., Ishise, H., Ueno, H., Oda, Y., . . Inoue, H. (2014). Slow and deep respiration suppresses steady-state sympathetic nerve activity in patients with chronic heart failure: From modeling to clinical application. AJP: Heart and Circulatory Physiology, 307(8), H1159-H1168. https://doi.org/10.1152/ajpheart.00109.2014

Holm, S. (1979). A simple sequentially rejective multiple test procedure. Scandinavian Journal of Statistics, 6(2), 65-70. https://doi. org/10.2307/4615733

Horsman, H. M., Peebles, K. C., \& Tzeng, Y. C. (2015). Interactions between breathing rate and low-frequency fluctuations in blood pressure and cardiac intervals. Journal of Applied Physiology, 119(7), 793-798. https://doi.org/10.1152/japplphysiol.00525.2015

Jackson, C. (2015). Trends in the use of complementary health approaches among adults in the United States: New data. Holistic Nursing Practice, 29(3), 178-179. https://doi.org/10.1097/ HNP.0000000000000088

Jafari, H., Courtois, I., Van den Bergh, O., Vlaeyen, J. W. S., \& Van Diest, I. (2017). Pain and respiration: A systematic review. Pain, 32(6), 28240995. https://doi.org/10.1097/j.pain.0000000000000865

Jones, C. U., Sangthong, B., \& Pachirat, O. (2010). An inspiratory load enhances the antihypertensive effects of home-based training with slow deep breathing: A randomised trial. Journal of Physiotherapy, 56(3), 179-186. https://doi.org/10.1016/S1836-9553(10)70023-0

Joseph, C. N., Porta, C., Casucci, G., Casiraghi, N., Maffeis, M., Rossi, M., \& Bernardi, L. (2005). Slow breathing improves arterial baroreflex sensitivity and decreases blood pressure in essential hypertension. Hypertension, 46(4), 714-718. https://doi.org/10.1161/01. HYP.0000179581.68566.7d 
Khayat, R. N., Przybylowski, T., Meyer, K. C., Skatrud, J. B., \& Morgan, B. J. (2004). Role of sensory input from the lungs in control of muscle sympathetic nerve activity during and after apnea in humans. Journal of Applied Physiology, 97(2), 635-640. https://doi. org/10.1152/japplphysiol.00241.2004\r00241.2004

Kim, S. H., Burge, M. R., Mermier, C., Kravitz, L., \& Schneider, S. M. (2016). Mind-body practices for posttraumatic stress disorder. Journal of Investigative Medicine, 61(5), 827-834. https://doi. org/10.2310/jim.0b013e3182906862

Kromenacker, B. W., Sanova, A. A., Marcus, F. I., Allen, J. J. B., \& Lane, R. D. (2018). Vagal mediation of low-frequency heart rate variability during slow yogic breathing. Psychosomatic Medicine, 80(6), 581-587. https://doi.org/10.1097/PSY.0000000000000603

Kubin, L., Alheid, G. F., Zuperku, E. J., \& McCrimmon, D. R. (2006). Central pathways of pulmonary and lower airway vagal afferents. Journal of Applied Physiology, 101(2), 618-627. https://doi. org/10.1152/japplphysiol.00252.2006

Laborde, S., Hosang, T., Mosley, E., \& Dosseville, F. (2019). Influence of a 30-day slow-paced breathing intervention compared to social media use on subjective sleep quality and cardiac vagal activity. Journal of Clinical Medicine, 8(2), 193. https://doi.org/10.3390/ jem8020193

Laitinen, T., Hartikainen, J., Vanninen, E., Niskanen, L., Geelen, G., \& Länsimies, E. (1998). Age and gender dependency of baroreflex sensitivity in healthy subjects. Journal of Applied Physiology, 84(2), 576-583. https://doi.org/10.1152/jappl.1998.84.2.576

Lakens, D. (2013). Calculating and reporting effect sizes to facilitate cumulative science: A practical primer for t-tests and ANOVAs. Frontiers in Psychology, 4(Nov), 1-12. https://doi.org/10.3389/ fpsyg.2013.00863

La Rovere, M. T., Pinna, G. D., \& Raczak, G. (2008). Baroreflex sensitivity: Measurement and clinical implications. Annals of Noninvasive Electrocardiology, 13(2), 191-207. https://doi. org/10.1111/j.1542-474X.2008.00219.x

Lehrer, P. M., Vaschillo, E., Vaschillo, B., Lu, S.-E., Eckberg, D. L., Edelberg, R., ... Hamer, R. M. (2003). Heart rate variability biofeedback increases baroreflex gain and peak expiratory flow. Psychosomatic Medicine, 65(5), 796-805. https://doi.org/10.1097/ 01.PSY.0000089200.81962.19

Mancia, G., \& Grassi, G. (2014). The autonomic nervous system and hypertension. Circulation Research, 114(11), 1804-1814. https:// doi.org/10.1161/CIRCRESAHA.114.302524

Mason, H., Vandoni, M., Debarbieri, G., Codrons, E., Ugargol, V., \& Bernardi, L. (2013). Cardiovascular and respiratory effect of yogic slow breathing in the yoga beginner: What is the best approach? Evidence-Based Complementary and Alternative Medicine, 2013, 743504. https://doi.org/10.1155/2013/743504

McCaul, K. D., Solomon, S., \& Holmes, D. S. (1979). Effects of paced respiration and expectations on physiological and psychological responses to threat. Journal of Personality and Social Psychology, 37(4), 564-571. https://doi.org/10.1037//0022-3514.37.4.564

Modesti, P. A., Ferrari, A., Bazzini, C., \& Boddi, M. (2015). Time sequence of autonomic changes induced by daily slow-breathing sessions. Clinical Autonomic Research, 25(2), 95-104. https://doi. org/10.1007/s10286-014-0255-9

Nielsen, R., Nikolajsen, L., Krøner, K., Mølgaard, H., Vase, L., Jensen, T. S., \& Terkelsen, A. J. (2015). Pre-operative baroreflex sensitivity and efferent cardiac parasympathetic activity are correlated with post-operative pain. Acta Anaesthesiologica Scandinavica, 59(4), 475-485. https://doi.org/10.1111/aas.12457

Oneda, B., Ortega, K. C., Gusmão, J. L., Araújo, T. G., \& Mion, D., Jr. (2010). Sympathetic nerve activity is decreased during deviceguided slow breathing. Hypertension Research, 33(Oct), 708-712. https://doi.org/10.1038/hr.2010.74

Pal, G. K., Velkumary, S., \& Madanmohan. (2004). Effect of short-term practice of breathing exercises on autonomic functions in normal human volunteers. Indian Journal of Medical Research, 120(2), $115-121$.

Pilowsky, P. M., \& Goodchild, A. K. (2002). Baroreceptor reflex pathways and neurotransmitters: 10 years on. Journal of Hypertension, 20(9), 1675-1688. https://doi.org/10.1097/00004872-20020 9000-00002

Pitzalis, M. (1998). Effect of respiratory rate on the relationships between RR interval and systolic blood pressure fluctuations: A frequency-dependent phenomenon. Cardiovascular Research, 38(2), 332-339. https://doi.org/10.1016/S0008-6363(98)00029-7

Raghuraj, P., \& Telles, S. (2008). Immediate effect of specific nostril manipulating yoga breathing practices on autonomic and respiratory variables. Applied Psychophysiology and Biofeedback, 33(2), 65-75. https://doi.org/10.1007/s10484-008-9055-0

Reyes Del Paso, G. A., Montoro, C., Muñóz Ladrón de Guevara, C., Duschek, S., \& Jennings, J. R. (2014). The effect of baroreceptor stimulation on pain perception depends on the elicitation of the reflex cardiovascular response: Evidence of the interplay between the two branches of the baroreceptor system. Biological Psychology, 101(1), 82-90. https://doi.org/10.1016/j.biops ycho.2014.07.004

Ring, C., Edwards, L., \& Kavussanu, M. (2008). Effects of isometric exercise on pain are mediated by blood pressure. Biological Psychology, 78(1), 123-128. https://doi.org/10.1016/j.biopsycho.2008. 01.008

Rosengård-Bärlund, M., Bernardi, L., Holmqvist, J., Debarbieri, G., Mäntysaari, M., af Björkesten, C. G., ... Groop, P. H. (2011). Deep breathing improves blunted baroreflex sensitivity even after 30 years of Type 1 diabetes. Diabetologia, 54(7), 1862-1870. https:// doi.org/10.1007/s00125-011-2164-y

Ryan, K. L., Cooke, W. H., Rickards, C. A., Lurie, K. G., \& Convertino, V. A. (2008). Breathing through an inspiratory threshold device improves stroke volume during central hypovolemia in humans. Journal of Applied Physiology, 104(5), 1402-1409. https://doi. org/10.1152/japplphysiol.00439.2007

Sangthong, B., Ubolsakka-Jones, C., Pachirat, O., \& Jones, D. A. (2016). Breathing Training for older patients with controlled isolated systolic hypertension. Medicine and Science in Sports and Exercise, 48(9), 1641-1647. https://doi.org/10.1249/MSS.00000 00000000967

Schulz, S., Adochiei, F.-C., Edu, I.-R., Schroeder, R., Costin, H., Bär, K.-J., \& Voss, A. (2013). Cardiovascular and cardiorespiratory coupling analyses: A review. Philosophical Transactions. Series A, Mathematical, Physical, and Engineering Sciences, 371, 20120191. https://doi.org/10.1098/rsta.2012.0191

Sin, P. Y. W., Galletly, D. C., \& Tzeng, Y. C. (2010). Influence of breathing frequency on the pattern of respiratory sinus arrhythmia and blood pressure: Old questions revisited. American Journal of Physiology. Heart and Circulatory Physiology, 298(5), H1588-H1599. https://doi.org/10.1152/ajpheart.00036.2010 
Spruyt, A., Clarysse, J., Vansteenwegen, D., Baeyens, F., \& Hermans, D. (2010). Affect 4.0: A free software package for implementing psychological and psychophysiological experiments. Experimental Psychology, 57(1), 36-45. https://doi.org/10.1027/1618-3169/a000005

Stankovski, T., Cooke, W. H., Rudas, L., Stefanovska, A., \& Eckberg, D. L. (2013). Time-frequency methods and voluntary rampedfrequency breathing: A powerful combination for exploration of human neurophysiological mechanisms. Journal of Applied Physiology, 115, 1806-1821. https://doi.org/10.1152/japplphysi ol.00802.2013

Stewart, J. M. (2012). Mechanisms of sympathetic regulation in orthostatic intolerance. Journal of Applied Physiology, 113, 1659-1668. https://doi.org/10.1152/japplphysiol.00266.2012

Szulczewski, M. T. (2019). An anti-hyperventilation instruction decreases the drop in end-tidal $\mathrm{CO} 2$ and symptoms of hyperventilation during breathing at $0.1 \mathrm{~Hz}$. Applied Psychophysiology and Biofeedback. Advance online publication. https://doi.org/10.1007/ s10484-019-09438-y

Szulczewski, M. T., \& Rynkiewicz, A. (2018). The effects of breathing at a frequency of $0.1 \mathrm{~Hz}$ on affective state, the cardiovascular system, and adequacy of ventilation. Psychophysiology, 55(12), 1-13. https://doi.org/10.1111/psyp.13221

Taha, B. H., Simon, P. M., Dempsey, J. A., Skatrud, J. B., \& Iber, C. (1995). Respiratory sinus arrhythmia in humans: An obligatory role for vagal feedback from the lungs. Journal of Applied Physiology, 78(2), 638-645. https://doi.org/10.1152/jappl.1995.78.2.638

Task Force of the European Society of Cardiology and the American Society of Pacing and Electrophysiology (Task Force). (1996). Heart rate variability: Standards of measurement, physiological interpretation, and clinical use. Circulation, 93(5), 1043-1065. https://doi.org/10.1161/01.CIR.93.5.1043

Tzeng, Y. C., Sin, P. Y. W., Lucas, S. J. E., \& Ainslie, P. N. (2009). Respiratory modulation of cardiovagal baroreflex sensitivity. Journal of Applied Physiology, 107(3), 718-724. https://doi.org/10.1152/ japplphysiol.00548.2009

Ubolsakka-Jones, C., Sangthong, B., Khrisanapant, W., \& Jones, D. A. (2017). The effect of slow-loaded breathing training on the blood pressure response to handgrip exercise in patients with isolated systolic hypertension. Hypertension Research, 40(10), 885-891. https ://doi.org/10.1038/hr.2017.54
Van Diest, I., Verstappen, K., Aubert, A. E., Widjaja, D., Vansteenwegen, D., \& Vlemincx, E. (2014). Inhalation/exhalation ratio modulates the effect of slow breathing on heart rate variability and relaxation. Applied Psychophysiology and Biofeedback, 39(3-4), 171-180. https://doi.org/10.1007/s10484-014-9253-x

Wager, T. D., Davidson, M. L., Hughes, B. L., Lindquist, M. A., \& Ochsner, K. N. (2008). Prefrontal-subcortical pathways mediating successful emotion regulation. Neuron, 59(6), 1037-1050. https:// doi.org/10.1016/j.neuron.2008.09.006

Wang, Y.-P., Kuo, T. B. J., Lai, C.-T., Chu, J.-W., \& Yang, C. C. H. (2013). Effects of respiratory time ratio on heart rate variability and spontaneous baroreflex sensitivity. Journal of Applied Physiology, 115(1), 1648-1655. https://doi.org/10.1152/japplphysi ol.00163.2013

Zou, Y., Zhao, X., Hou, Y.-Y., Liu, T., Wu, Q., Huang, Y.-H., \& Wang, X.-H. (2017). Meta-analysis of effects of voluntary slow breathing exercises for control of heart rate and blood pressure in patients with cardiovascular diseases. American Journal of Cardiology, 120(1), 148-153. https://doi.org/10.1016/j.amjcard.2017.03.247

\section{SUPPORTING INFORMATION}

Additional supporting information may be found online in the Supporting Information section at the end of the article.

\section{Appendix S1 \\ Figures S1-S4 \\ Tables S1-S4}

How to cite this article: Gholamrezaei A, Van Diest I, Aziz Q, Vlaeyen JWS, Van Oudenhove L. Influence of inspiratory threshold load on cardiovascular responses to controlled breathing at $0.1 \mathrm{~Hz}$. Psychophysiology. 2019;56:e13447. https://doi. org/10.1111/psyp.13447 